\title{
Application of Steel Structure in Coal in Architecture
}

\author{
Jiang Shu \\ Chongqing Vocational Institute of Engineering, Chongqing, 400037, China
}

\author{
Keywords: Steel structure; Coal mine; Construction; Application
}

\begin{abstract}
The steel body structure is one of the widely used in building structure at present, its advantage is very prominent, and to a certain extent, applied to coal mine construction. Coal mine buildings, generally requires a material with special requirement. Therefore, for the steel structure, in the coal mine construction, will highlight its advantages. This paper introduces the characteristics of steel structure, and starting from the actual coal mine construction, the effective combination of points for both. Finally, the effective analysis of the relationship between the construction safety and steel structure in coal mine, in order to clear the role of steel structure.
\end{abstract}

\section{Introduction}

As the steel construction theory and technology is getting increasingly mature, the steel construction system has been widely applied in the architecture,metallurgy. As the nation and people is now paying more and more attention to the land resources,the Ministry of construction has already stop the use of the clay brick, currently, the annual production of the steel now has reached 716 million, which account for half of the global production, the demand is far below the supply, the Ministry of construction also pointed out that China will vigorously develop the steel construction architecture, Under such background, most of the building still is the traditional structure architecture, which can not meet the develop needs of the modern coal mine, so adopting steel construction architecture could promote the development and construction of the coal mine.

\section{Steel construction briefing}

In some developed countries, the steel construction has been widely applied in all kinds of building, the most famous case is the Eiffel Tower in France, the Empire State in NY,USA and the golden gate bridge, they are all the steel construction architecture. The steel construction in China starts very late, but we have built some large projects like national gym(bird nest)and national swim center(water cubic). Compared to the traditional structure system, the steel structure is a new-type structure system, most of the components adopted is the economic material, it enjoys several advantages compared to the traditional architecture structure system:

\section{Economic Advantages}

In the steel construction architecture, the design and processing procedure usually adopt the advanced methods, the production of the components in the architecture adopts large-scale production mode.Compared to the traditional structure system, the architecture cost were reduced greatly,people can draw benefit from the investment on the architecture faster.

\section{Anti-seismic advantage}

The components applied in the steel construction is lighter compared to the traditional clay brick and concrete. So, the effect of the seismic is reduced, at the same time,the steel in the steel structure has high tensity and excellent ductility, if all the components in the building is adjusted,and the deformability is optimized, then the security of the steel construction will be optimized. When there happened some accidents, the steel in the steel construction will be deformed first, it is easy to notice that the in-time evacuation could avoid such accident to some degree.

\section{Space advantage}

Because the steel construction architecture is relatively flexible, in the coal architecture could design according to the coal equipment installation, especially the architecture on the coal mine 
surface, the wall can not play the load-bearing role, the layout of the house is even more flexible, the inner space in the steel structure is even more spacious compare to the traditional structure, and it has the maximum span about 60 meters. The renovation and expansion is also more flexible, this also facilitates the deployment of the pipes in the coal mine.

\section{Advantage of environmental protection}

Most of the material in the steel construction is steel, so, if the architecture is removed, this steel can be recycled, after the processing, it can be used again, it is environmental friendly and land-conservative as well.

\section{Steel Construction System}

\section{Supporting System}

According to the character and layer of the building, the supporting system can be classified into space frame, flat frame,portal frame,etc. If the building is a monolayer workshop building, it usually is very demanding for the span, the steel structure can adopt portal frame system, and the bent frame system theoretically, but we found out in the real construction work that the portal frame system is actually more efficient than the steel structure, and the portal frame system is smaller, faster to install,the cost of the material is relatively smaller. When the building is not monolayer structure, this building will has relatively small span,its supporting system could adopt frame structure, when it comes to the multilayer and monolayer connected situation,in case the discoordination occurred after the two building was deformed, the frame stiffness should be enhanced.

\section{Floor system}

If the steel structure architecture is used in the coal mine building, the stiffness and strength will directly effect the stability of the building. So special attention must be attached, during the construction work, it is also needed to control the weight of the floor, thus the construction schedule could be improved largely, by the actual construction analysis, we can see that the floor of the steel structure usually will adopt the steel, prefabricated composite, The cast-in-place reinforced concrete or lightweight aggregate combine the cast-in-place reinforced concrete. No matter what kind is adopted,the link between the floor and beam surface is the most important.if the steel floor is adopted, there should be some supporting added to make up this shortcoming for its small plate stiffness. While adopting the prefabricated plate laminated flooring could make the construction speed rather quick for the mode is not necessary. Adopting the cast in concrete composite combination floor could well control the weight of the floor,the cast-in concrete composite is the best methods among all the four floor, but due to its heaviness, it is impossible to be applied in the smaller houses,therefore, in the current building system, the building with relatively large supporting capacity will adopt the cast-in place concrete floor, and those with relatively small supporting capacity will adopt the prefabricated plate laminated flooring.

\section{Enclosure structure system}

The enclosure structure in the steel structure usually will adopt wall,floor and roof material. Among them, the wall and floor construction usually will adopt multi-colors pressure plate and space plate etc.while the roof adopts the edge-rolling C-shape steel and Z-shape steel to connect to the main body of the architecture. The enclosure structure could make sure the coordination and ruggedness of building, as for the whole steel structure, it usually need the hard architecture wall,So, we could also analysis it according to the actual needs,

The enclosure structure is beneficial to the steel structure in the coal mine building. So the steel structure must be anti-pressure, shock-resistant, and antiriot. The main reason is through the control of this factor, we could effectively avoid the coal mine security`s effect to the coal mine building, and reduce the lost as much as possible. 


\section{Characters of the coal mine architecture}

The coal mine buildings are usually divided into industry building and civil building, among them, many civil architecture`s demand is relatively simple, as long as it can meet the basic needs, during the construction,there are also many different structure forms, currently, most of the coal mine civil architecture adopts concrete frame and multi-layers brick structure, but in the real coal mine, there are few civil buildings compared to industry buildings, the coal itself is productive, so most of the coal mine building is for industry use, by investigating and analyzing the industry building in Fax coal mine, the industry buildings have the following basic characters, the storeies of the building are relatively low, there are not any building with more than 3 floors, most of them are monolayer with large span; the second is the basic facilities are placed on the ground, which has a very small load to the architecture,and there are lifting equipments in some buildings, the lifting weight is under 20 tonners; at last, due to its special property, there are many sections in the coal mining,the fundamental construction work is enormous, if the traditional architecture is adopted,the construction cost is very high.

Currently, the coal mine building structure mostly adopts traditional concrete frame,bent, which is very land-consuming during the construction, and it will cause some pollution to the surrounding area, the construction period is relatively longer, Under the background of new century, the traditional structure can no longer meet the needs of modern coal mines. So, it is necessary to introduce a new architecture mode so as to satisfy people`s needs for modern coal mine.

\section{The application of steel structure architecture in the coal mine building}

From the character and advantage of the steel structure architecture, we can see that compared to traditional architecture, if the steel structure building is applied to the coal mine building, the competitiveness of the coal mine can be improved in economic, earthquake-resistance, extensity, and environmental friendliness. Besides, the steel construction architecture is not simply the needs for coal mine economic benefits, it is also the needs of out time, From the analysis of the coal mine architecture we can draw the conclusion that the steel construction architecture can be widely used in the coal mine building, such as the by-pit heapstead construction, for its special property, it will cause great vibration to the surrounding land and lead to the soft soil situation, if we continue the construction work with the traditional concrete structure would lead to some safety issue for the soft soil.

If conducting some processing work to the soft soil before using the concrete structure construction, this practice would increase the construction cost, and cause some delay to the construction period, if adopting the steel structure architecture, this problem can be solved by using some light material with good ductility. This can not only make sure the normal construction of the coal mine, but also reduce the construction cost to some degree.From which we can see that applying the steel construction into the coal mine can remove many problems in the traditional architecture structure, and it also improves the efficiency of the construction work as well.

\section{Conclusion}

As the steel structure becomes more and more widely applied, using the steel structure in coal mine architecture has already become a trend,compared to the traditional architecture form. The steel structure buildings enjoy many advantages, but we should also pay attention to some problems in the actual construction process, such as the anticorrosion and heat-resistivity of the steel construction is relatively weaker compared to the traditional concrete, but after long-time practice work, now people have figured out many solution.such as painting a protection oil onto its surface, as a new-type architecture system, it still needs people`s continuous research, by bringing the design, construction and all the factors into full paly, thus to take full advantage of the steel structure building. 


\section{References}

[1] Cao Jianguo, Gao Benqing, Li Shizhong, Yang Kang, Wang Liang, Wang Wei: Exploration of Quanshang coal mining technology under coal mine buildings, Modern Mining, 2012(06):60-63

[2] Guo Baizhuang, Han Renqiao, Xing Shuqin: Shandong Longkou strip mining under the coal mine building, Geotechnical Engineering World 2008(02):44-46

[3] Yin Xiangtai, Li Xinhua, Zheng Diansong,Yan Shijie: Exploration of the coal mining technology plan under Liang jia coal mine building, Mine Surveying, 2004(04):7-9 